\title{
Comparison of Sevoflurane and Propofol for Laryngeal Mask Airway Insertion
}

\author{
Partha Debbarma ${ }^{1}$, Joydeep Debnath ${ }^{2}$ \\ 1,2 Department of Anaesthesiology, AGMC, Agartala, Tripura, India.
}

\section{ABSTRACT}

\section{BACKGROUND}

Propofol is an appropriate intravenous anaesthetic induction agent for rapid induction and suppression of airway reflexes and is widely used for laryngeal mask airway insertion. Sevoflurane is a halogenated, non-pungent and non-explosive liquid anaesthetic agent with low blood gas solubility administered by inhalation for use in induction and maintenance of general anaesthesia. We wanted to compare the characteristics of sevoflurane and propofol for the induction of anaesthesia and laryngeal mask airway (LMA) insertion.

\section{METHODS}

We conducted a randomized control study among 70 patients ( $\mathrm{n}=35$ in each group) undergoing elective surgery. Patients were anaesthetised with either vital capacity breaths of $8 \%$ sevoflurane with $50 \% \mathrm{~N}_{2} \mathrm{O}$ and $\mathrm{O}_{2}$ or IV propofol, with loss of eyelash reflex considered as the end point of induction.

\section{RESULTS}

Both the drugs produced almost similar rapid loss of consciousness (propofol-45.29 $\pm 11.98 \mathrm{sec}$, sevoflurane-51.03 $\pm 14.68 \mathrm{sec}$ ). The LMA was inserted more rapidly in propofol group $(20.43 \pm 9.460 \mathrm{sec})$ than in the sevoflurane group $(34.37 \pm 17.338$ sec), $p=0.018$. The score for jaw opening was better in the propofol group $(2.94 \pm$ $0.236)$ than in the sevoflurane group $(2.66 \pm 0.482), p=0.000$. The ease of LMA insertion score was better in the propofol group $(2.91 \pm 0.284)$ than in the sevoflurane group $(2.66 \pm 0.482), p=0.008$. Both groups had stable haemodynamic parameters.

\section{CONCLUSIONS}

Propofol was more favourable than sevoflurane for laryngeal mask airway insertion due to better jaw relaxation and less insertion time. However, sevoflurane is an alternative to propofol as an induction agent for laryngeal mask airway insertion.
Corresponding Author: Dr. Joydeep Debnath, Dhaleswar, Road No.9, Agartala-799007, Tripura (W), India. E-mail: jdebnath797@gmail.com

DOI: $10.14260 / \mathrm{jemds} / 2022 / 75$

How to Cite This Article:

Debbarma P, Debnath J. Comparison of sevoflurane and propofol for laryngeal mask airway insertion. J Evolution Med Dent Sci 2022;11(03):391-395, DOI: 10.14260/jemds/2022/75

Submission 02-01-2017,

Peer Review 05-02-2022,

Acceptance 12-02-2022,

Published 14-02-2022.

Copyright (C) 2022 JEMDS. This is an open access article distributed under Creative Commons Attribution License [Attribution 4.0 International (CC BY 4.0)]

\section{KEY WORDS}

Propofol, Sevoflurane, Laryngeal Mask Airway. 


\section{BACKGROUND}

Airway management is one of the most important skills in the field of anaesthesiology, and inability to secure the airway can lead to catastrophic results. Before 1990, only the face mask and the endotracheal tube were the available airway devices. Since then, several supraglottic airway devices have been developed, of which the laryngeal mask airway (LMA) is the most popular one. The laryngeal mask airway has gained popularity as a general-purpose airway device and is currently used for routine elective surgical procedures as frequently as the tracheal tube. Compared with the tracheal tube, the laryngeal mask airway is easy to place, does not require muscle relaxation and laryngoscopy, and may prevent complications associated with tracheal tube. ${ }^{1}$ Several workers observed successful insertion of the laryngeal mask airway without any unwanted effects, such as coughing and gagging requires adequate depth of anaesthesia and suppression of the upper airway reflexes. ${ }^{2-5}$ The laryngeal mask airway can be easily inserted following an intravenous induction with propofol or inhalation induction with sevoflurane. $3,4,6,7,8,9$

Propofol is an intravenous sedative-hypnotic agent for use in the induction and maintenance of anaesthesia or sedation. Intravenous injection of a therapeutic dose of propofol induces hypnosis with minimal excitation, usually within 40 secs.

Sevoflurane is an alternative to propofol for induction of anaesthesia because it has a pleasant odour, does not irritate the airways, provides smooth and rapid induction and recovery, and has a lower incidence of apnea.2,5 Several studies have shown that induction of anaesthesia after inhalation of sevoflurane is comparable with intravenous propofol. ${ }^{5}$ Patients administered sevoflurane showed shorter times to some recovery events ${ }^{1}$ (extubation, response to command and orientation) than patients who received isoflurane or propofol. However, inhalation induction with sevoflurane without any co-induction agents produces more excitation before insertion of laryngeal mask airway and takes more time to produce jaw relaxation.

Hence, the present study has been taken up to compare the characteristics of sevoflurane and propofol for laryngeal mask airway insertion.

\section{METHODS}

A randomised control trial was done from January 2015 to June 2016 in the Department of Anaesthesiology, Regional Institute of Medical Sciences, Imphal, Manipur. After approval of the institutional ethics committee and obtaining informed consent from the patients concerned, the study was conducted among patients with ASA physical status I or II, aged between 18 and 60 years of both genders, undergoing elective surgery under general anaesthesia.

Patients with history of cardiovascular, pulmonary or renal dysfunction, pregnant women or breastfeeding mothers, smokers, patients with drug allergy, suspicion of malignant hyperthermia or patients who lacked cooperation were excluded from the study.
Based on a study by Priya $V$ et al. ${ }^{4}$ the sample size for our study was 35 in each group, assuming the $\alpha$ value of 0.05 and $\beta$ value of 0.2 (power of study $=1-\beta=0.8$ i.e., $80 \%$ ).

Patients were allocated to two groups using computer generated randomization method. On arrival in the preoperative room haemodynamic parameters were evaluated. Every patient received intramuscular midazolam $[0.07$ $\mathrm{mg} / \mathrm{kg}$ ) half an hour prior to induction of anaesthesia followed by haemodynamic monitoring. Intravenous access was established and the slow infusion of crystalloids was commenced in the pre-operative room.

Prior to the induction of anaesthesia, patients in both the groups were having a face mask placed over their face and were breathing spontaneously. Group A (propofol) received intravenous propofol (mean dosage - $2.5 \mathrm{mg} / \mathrm{kg}$ body weight) with $100 \%$ oxygen via the face mask. In Group B (sevoflurane), the Magills circuit was primed with sevoflurane $8 \%$ in $\mathrm{N}_{2} \mathrm{O} 50 \%$ and $\mathrm{O}_{2}$ (flow rate -8 litres $/ \mathrm{min}$.) for 30 seconds. Each patient was asked to exhale maximally and the primed circuit was then connected to the face mask. They were asked to take vital capacity breaths.

Loss of eyelash reflex was considered as the end point of induction in both the groups. Intravenous fentanyl (2 $\mathrm{mcg} / \mathrm{kg}$ ) was injected immediately after loss of eyelash reflex and laryngeal mask airway insertion was attempted by an experienced anaesthesiologist being blinded to the induction technique. He stayed outside the anaesthetic room during the initial induction period and was called after the loss of eyelash reflex for the insertion of the laryngeal mask airway. If the first attempt was unsuccessful and there was a requirement for more anaesthetic, he left the room and was recalled for laryngeal mask airway placement after the repeat administration of either propofol or sevoflurane.

The time for induction i.e., the time (in sec.) taken from induction of anaesthesia to the loss of eyelash reflex, and the time for laryngeal mask airway insertion i.e., the time (in secs.), taken from loss of eyelash reflex to laryngeal mask airway insertion were recorded in both the groups.

Haemodynamic parameters (mean arterial pressure and heart rate) were recorded at baseline, at induction and every minute for 5 minutes after induction for Group A and Group B.

\section{Statistical Analysis}

Statistical analysis was performed using Student's unpaired ttest for demographic data and haemodynamic changes. Chisquare test incorporating Fishers exact test and the MannWhitney test were used for the variables of induction, quality of laryngeal mask airway insertion. P value $<0.05$ was taken as statistically significant. Analysis of the total scores for conditions of laryngeal mask airway insertion were performed along with the individual scores for criteria of laryngeal mask airway insertion and the patient's response.

\section{RESULTS}

The two groups were comparable in terms of demographic profile (Table 1) and there were no statistically significant differences in terms of age, sex, weight and ASA grading $(p>0.05)$. 


\begin{tabular}{|c|c|c|c|c|c|c|}
\hline $\begin{array}{l}\text { Para- } \\
\text { meters }\end{array}$ & $\begin{array}{c}\text { Group A } \\
(n=35)\end{array}$ & $\begin{array}{c}\text { Group B } \\
(n=35)\end{array}$ & $\begin{array}{c}\text { Statistical Test } \\
\text { Value }\end{array}$ & df & $\begin{array}{c}\text { p } \\
\text { Value }\end{array}$ & Inference \\
\hline Age (years) & $\begin{array}{l}39.26 \pm \\
11.954\end{array}$ & $\begin{array}{c}40.63 \pm \\
12.659\end{array}$ & Ind t test 0.144 & 68 & 0.643 & NS \\
\hline Sex (M: F) & $9: 26$ & $4: 31$ & Chi square 2.362 & 1 & 0.124 & NS \\
\hline Weight $(\mathrm{kg})$ & $55 \pm 9.274$ & $53.71 \pm 8.567$ & Ind t test 0.434 & 68 & 0.549 & NS \\
\hline ASA (I: II) & $32: 3$ & $35: 0$ & Chi square 3.134 & 1 & 0.077 & NS \\
\hline \multicolumn{7}{|c|}{ Table 1. Demographic Profile } \\
\hline
\end{tabular}

\begin{tabular}{|c|c|c|c|c|c|c|}
\hline Parameters & $\begin{array}{l}\text { Group A } \\
(n=35)\end{array}$ & $\begin{array}{l}\text { Group B } \\
(n=35)\end{array}$ & $\begin{array}{l}\text { Statistical } \\
\text { Test Value }\end{array}$ & df & $\begin{array}{c}\text { p } \\
\text { Value }\end{array}$ & Inference \\
\hline $\begin{array}{c}\text { Time of } \\
\text { induction (sec) }\end{array}$ & $\begin{array}{c}45.29 \pm \\
11.98\end{array}$ & $\begin{array}{c}51.03 \pm \\
14.68\end{array}$ & $\begin{array}{c}\text { Ind t test } \\
0.816\end{array}$ & 68 & 0.078 & NS \\
\hline $\begin{array}{c}\text { Time of } \\
\text { insertion (sec) }\end{array}$ & $\begin{array}{c}20.43 \pm \\
9.460 \\
\end{array}$ & $\begin{array}{l}34.37 \pm \\
17.338 \\
\end{array}$ & $\begin{array}{c}\text { Ind t test } \\
7.292 \\
\end{array}$ & 68 & 0.018 & S \\
\hline
\end{tabular}

There were no statistically significant differences between the induction time or time of loss of consciousness in both the groups. However, the mean time taken for induction in the sevoflurane group was higher (51.03 \pm 14.68 sec) compared to the propofol group ( $45.29 \pm 11.98 \mathrm{sec}), \mathrm{p}=$ 0.078 .

The mean time of intubation, i.e., LMA insertion was much less in the propofol group $(20.43 \pm 9.460 \mathrm{sec})$ in comparison with sevoflurane group $(34.37 \pm 17.338 \mathrm{sec})$ which was statistically significant, $\mathrm{p}=0.018$.

After analysis of the individual scores for conditions of laryngeal mask airway insertion (Table 3), it was observed that jaw opening was much better in the propofol group (mean score- $2.94 \pm 0.236$ ) compared to the sevoflurane group (mean score- $2.66 \pm 0.482$ ), which was statistically highly significant, $\mathrm{p}-0.000$.

\begin{tabular}{|c|c|c|c|c|c|c|}
\hline Parameters & $\begin{array}{c}\text { Group A } \\
(n=35)\end{array}$ & $\begin{array}{c}\text { Group B } \\
(n=35)\end{array}$ & $\begin{array}{l}\text { Statistical } \\
\text { Test Value }\end{array}$ & df & $\begin{array}{c}\text { p } \\
\text { Value }\end{array}$ & Inference \\
\hline $\begin{array}{l}\text { Jaw opening } \\
\text { (score) }\end{array}$ & $2.94 \pm 0.236$ & $2.66 \pm 0.482$ & $\begin{array}{c}\text { Ind t test } \\
61.945\end{array}$ & 68 & 0.000 & HS \\
\hline $\begin{array}{c}\text { Ease of LMA } \\
\text { insertion (score) }\end{array}$ & $2.91 \pm 0.284$ & $2.66 \pm 0.482$ & $\begin{array}{c}\text { Ind } t \text { test } \\
38.608\end{array}$ & 68 & 0.008 & S \\
\hline Coughing (score) & $3.00 \pm 0.00$ & $3.00 \pm 0.00$ & $\begin{array}{c}\text { Ind t test } \\
0.00\end{array}$ & 0 & 0.00 & NS \\
\hline Gagging (score) & $3.00 \pm 0.00$ & $3.00 \pm 0.00$ & Ind t test 0.00 & 0 & 0.00 & NS \\
\hline $\begin{array}{l}\text { Laryngospasm } \\
\text { (score) }\end{array}$ & $3.00 \pm 0.00$ & $2.97 \pm 0.169$ & $\begin{array}{l}\text { Ind t test } \\
4.246\end{array}$ & 68 & 0.321 & NS \\
\hline $\begin{array}{l}\text { Limb and head } \\
\text { movements } \\
\text { (score) }\end{array}$ & $2.83 \pm 0.453$ & $2.91 \pm 0.284$ & $\begin{array}{c}\text { Ind } t \text { test } \\
3.838\end{array}$ & 68 & 0.346 & NS \\
\hline
\end{tabular}

\begin{tabular}{|c|c|c|c|c|c|}
\hline Parameters & Score & Description & $\begin{array}{c}\text { Group A } \\
(n=35)\end{array}$ & $\begin{array}{c}\text { Group B } \\
(n=35)\end{array}$ & P Value \\
\hline \multirow{3}{*}{ Jaw opening } & 3 & Full & 33 (94\%) & $23(65 \%)$ & \multirow{3}{*}{0.006} \\
\hline & 2 & Partial & $2(5 \%)$ & $12(34 \%)$ & \\
\hline & 1 & Nil & 0 & 0 & \\
\hline \multirow{3}{*}{$\begin{array}{l}\text { Ease of LMA } \\
\text { insertion }\end{array}$} & 3 & Easy & 32 (91\%) & $23(65 \%)$ & \multirow{3}{*}{0.018} \\
\hline & 2 & Difficult & $3(8 \%)$ & $12(34 \%)$ & \\
\hline & 1 & Impossible & 0 & 0 & \\
\hline \multirow{3}{*}{ Coughing } & 3 & Nil & $35(100 \%)$ & $35(100 \%)$ & \\
\hline & 2 & Minor & 0 & 0 & \\
\hline & 1 & Severe & 0 & 0 & \\
\hline \multirow{3}{*}{ Gagging } & 3 & Nil & $35(100 \%)$ & $35(100 \%)$ & \\
\hline & 2 & Minor & 0 & 0 & \\
\hline & 1 & Severe & 0 & 0 & \\
\hline \multirow{3}{*}{$\begin{array}{l}\text { Laryngospasm/ } \\
\text { obstruction }\end{array}$} & 3 & Nil & $35(100 \%)$ & $34(97 \%)$ & \multirow{3}{*}{1.00} \\
\hline & 2 & Partial & 0 & $1(3 \%)$ & \\
\hline & 1 & Total & 0 & 0 & \\
\hline \multirow{3}{*}{$\begin{array}{l}\text { Limb/head } \\
\text { movements }\end{array}$} & 3 & Nil & $30(85 \%)$ & 32 (91\%) & \multirow{3}{*}{0.547} \\
\hline & 2 & Moderate & $4(11 \%)$ & $3(8 \%)$ & \\
\hline & 1 & Vigorous & $1(3 \%)$ & 0 & \\
\hline & Com & $\begin{array}{l}\text { rison of Cono } \\
\text { between Tw }\end{array}$ & $\begin{array}{l}\text { ditions for } \\
\text { o Groups }\end{array}$ & MA Insertic & \\
\hline
\end{tabular}

The ease of laryngeal mask airway insertion was statistically significant, $\mathrm{p}-0.008$, which was much better in the propofol group with a mean score of $2.91 \pm 0.284$ as compared to the sevoflurane group which had a mean score of $2.66 \pm 0.482$.

When we compared the conditions for laryngeal mask airway insertion individually in both the groups, as shown in Table 4, it was observed that 33 patients (94\%) had full jaw relaxation in the propofol group whereas 23 patients $(65 \%)$ had full jaw relaxation in the sevoflurane group. It was easy for insertion of laryngeal mask airway in 32 patients (91\%) in the propofol group, compared to the sevoflurane group which was 23 patients $(65 \%)$.

However, 4 patients $(11 \%)$ in the propofol group showed moderate limb/head movements whereas 3 patients $(08 \%)$ showed moderate movements in the sevoflurane group. 1 patient (3\%) had vigorous limb/head movements in the propofol group whereas it was none in the sevoflurane group.

Partial laryngospasm was observed in 1 patient $(3 \%)$ in the sevoflurane group whereas it was none in the propofol group.

There was no statistically significant difference in mean arterial pressure and heart rate values between the two groups after induction and both the groups exhibited stable mean arterial pressure and heart rate values (Figure 1 and 2).

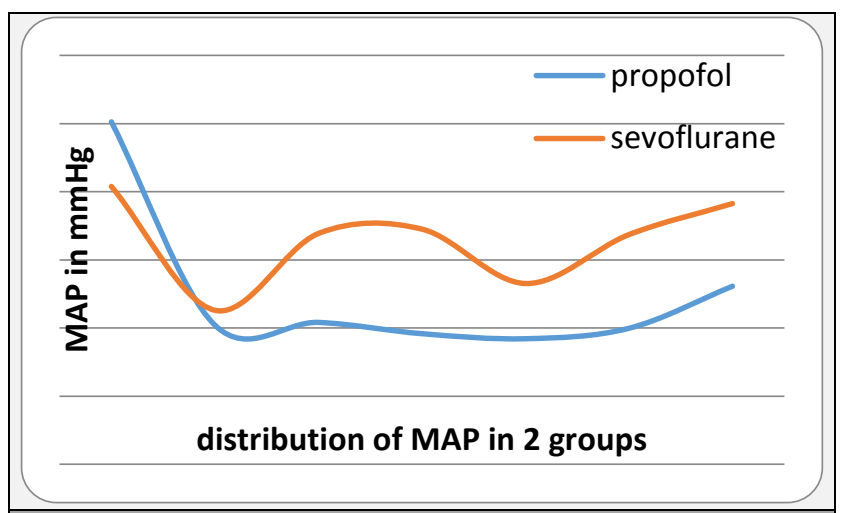

Figure 1. Comparison of Mean Arterial Pressure between Two Groups

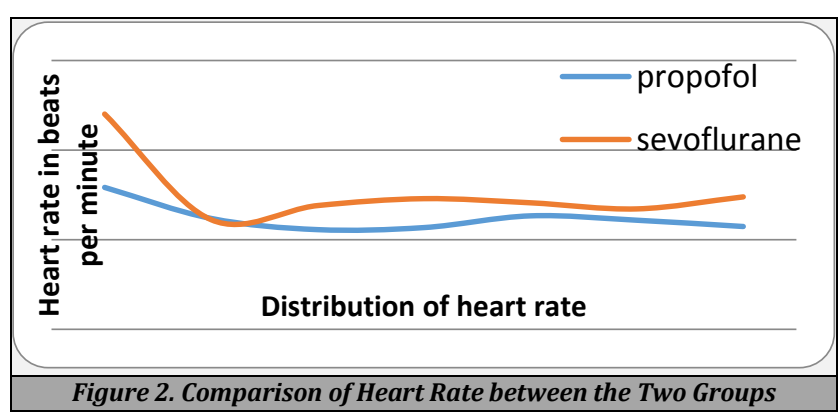

\section{DISCUSSION}

No statistically significant differences were observed between the two groups in terms of demographic profile except that the number of female patients were more in both the groups compared to male patients. Other parameters like age, weight and ASA class were almost similar in both the groups $(\mathrm{p}>0.05)$. 
Scanlon $\mathrm{P}$ et al. ${ }^{1}$ in their study observed that there was better jaw relaxation in the propofol group than in the sevoflurane group. Similar findings were also reported by Kati I et al. ${ }^{2}$ where adequate jaw opening was achieved in both groups and no difficulty in laryngeal mask airway was encountered. In our study the jaw opening was highly significant $(\mathrm{p}=0.000)$, with the propofol group $(2.94 \pm 0.236)$ scoring better than the sevoflurane group $(2.66 \pm 0.482)$. The jaw opening in this present study was full in $94 \%$ of the patients in the propofol group and $65 \%$ in the sevoflurane group respectively. However, the jaw opening was partial in $5 \%$ of the patients in the propofol group and $34 \%$ in sevoflurane group and was statistically significant $(\mathrm{p}=0.006)$. Our findings were comparable to that of Priya $\mathrm{V}$ et al.3,4 who reported full jaw relaxation in $72 \%$ of the patients in propofol group and $44 \%$ in sevoflurane group.

The difference in jaw relaxation between the propofol and sevoflurane groups could have been due to the fact that patients in the propofol group received more anaesthetic, as equipotent doses of both drugs could not be determined. Another likely explanation for the poor jaw opening in the sevoflurane group is the lag time during which the alveolar concentration of sevoflurane equilibrates with the brain, which results in inadequate anaesthesia during the initial attempt at insertion.

In the present study, the score for ease of laryngeal mask airway insertion was also better in the propofol group $(2.91 \pm$ $0.284)$ compared to the sevoflurane group $(2.66 \pm 0.482)$ which was statistically significant $(p=0.008)$. Laryngeal mask airway insertion was easy in $91 \%$ of the patient in propofol group and $65 \%$ in sevoflurane group respectively which was statistically significant $(p=0.018)$. Our findings were comparable to that of Priya V et al. ${ }^{4}$ who observed easy laryngeal mask airway insertion in $96 \%$ of the patient in propofol group and $80 \%$ in sevoflurane group respectively. Similar study was done by Sivalingam P et al. ${ }^{3}$ who observed easy insertion in $80 \%$ of the patient in propofol group and $80 \%$ in sevoflurane group respectively. However, they also observed difficult insertion in $16 \%$ of the patient in propofol group and $20 \%$ in sevoflurane group respectively. In their study Kati I et al. ${ }^{2}$ observed that there was no statistical difference between the two groups in terms of mean arterial pressure and heart rate which were consistent with our findings. Priya V et al. ${ }^{4}$ also compared the haemodynamic parameters between the two groups and found that both the groups exhibited stable haemodynamic profiles. However, they reported a statistically significant difference in the mean arterial pressure in the propofol group, 3 minutes after induction which was not the case in our study.

Scanlon $\mathrm{P}$ et al. ${ }^{1}$ found that incidences of gagging, laryngospasm and head/limb movements were much less in the propofol group than in the sevoflurane group. In our study, although there were no incidences of coughing and gagging in either of the two groups, one incidence of laryngospasm (3\%) was encountered in the sevoflurane group.

Intubating conditions for the laryngeal mask airway using sevoflurane compared favourably with propofol in a number of studies by Mary E M et al. ${ }^{5}$ Lian $\mathrm{K}$ T et al. ${ }^{6}$ However, taking the same end point of induction, which is the loss of eyelash reflex in both the groups, conditions for laryngeal mask airway insertion were superior with propofol compared to sevoflurane. We also found that the induction time was longer with sevoflurane than with propofol which was comparable to the study by Priya $\mathrm{V}$ et al. ${ }^{4}$ and Lian $\mathrm{K} T$ et al. ${ }^{6}$

In a study by Mary E M et al. ${ }^{5}$ they found that the time for laryngeal mask airway insertion was much longer in the sevoflurane group, 2.2 (1-3) min than in the propofol group, 1.3 (1-3) min, and was statistically significant $(\mathrm{p}<0.05)$, which was comparable to the findings by Sivalingam $\mathrm{P}$ et $\mathrm{al}^{3}$ [Propofol - 149.2(130-167) sec; Sevoflurane - 184.4 (154214) sec]. Lian K. T et al. ${ }^{6}$ also found that the laryngeal mask airway was inserted more rapidly in the propofol group $(74 \pm 29 \mathrm{sec})$ than in the sevoflurane group $(127 \pm 35 \mathrm{sec})$ which was statistically significant $(p<0.01)$. In our study the time taken for insertion of the laryngeal mask airway was also much less in the propofol group $(20.43 \pm 9.460 \mathrm{sec})$ than in the sevoflurane group $(34.37 \pm 17.338 \mathrm{sec})$ which was statistically significant $(\mathrm{p}=0.018)$. This might be due to the inadequate jaw relaxation with sevoflurane as propofol is known to have a relaxant effect on jaw muscles whereas inhalational anaesthetics may cause an increased muscle tone and spasticity. So, for the end point of induction i.e., loss of eyelash reflex, there might be better jaw relaxation with propofol.

The incidence of limb/head movements in our study was higher in the propofol group (14\%) than in the sevoflurane group (8\%) as compared to the study done by Scanlon P et al. ${ }^{1}$ where the incidence of head and limb movements were $11 \%$ and $20 \%$ respectively. However, Smith I and Thwaites A.J observed that propofol (55\%) was associated with a higher incidence of intra-operative movements than sevoflurane $(10 \%)$ which is consistent with our study. Sahar M.S et al. ${ }^{7}$ also observed that movements during laryngeal mask airway insertion were more in propofol group (50\%) compared to the sevoflurane group (19\%).

\section{CONCLUSIONS}

In conclusion, we found that induction of anaesthesia with propofol was better than sevoflurane for laryngeal mask airway insertion using the loss of eyelash reflex as the end point of induction. However, sevoflurane is an alternative induction agent to propofol for laryngeal mask airway insertion as it allows spontaneous breath during induction in patients with a potentially difficult airway. Moreover, complications are not higher than propofol but it may result in a longer time for insertion of the laryngeal mask airway.

\section{Limitations}

1. The number of times at which LMA insertion was attempted is not defined. More attempts may interfere with the sympathetic response.

2. The study was randomized but not blinded; therefore, there is a possibility of observer bias.

3. We did not measure the depth of anaesthesia and this stands out as a limitation of our study as we employed two different methods of induction.

4. Cost incurred by the both the study groups was not evaluated. 


\section{REFERENCES}

[1] Scanlon P, Carey M, Power M. Patient response to laryngeal mask insertion after induction of anaesthesia with propofol or thiopentone. Can J Anaesth 1993;40(9):816-8.

[2] Kati I, Demirel CB, Huseyinoglu UA, et al. Comparison of propofol and sevoflurane for laryngeal mask airway insertion. Tohoku J Exp Med 2003;200(3):111-8.

[3] Sivalingam P, Kandasamy R, Madhavan G, et al. Conditions for laryngeal mask insertion. A comparison of propofol versus sevoflurane with or without alfentanil. Anaesthesia 1999;54(3):271-6.

[4] Priya V, Divatia JV, Dasgupta D. A comparison of propofol versus sevoflurane for laryngeal mask airway insertion. Indian J Anaesth 2002;46(1):31-4.
[5] Mary EM, Buggy DJ, Scanlon P. Propofol or sevoflurane for laryngeal mask airway insertion. Can J Anesth 1999;46(4):322-6.

[6] Lian KT, Chow MY, Lee TL. Comparison of sevoflurane with propofol for laryngeal mask airway insertion in adults. Anesth Analg 1999;88(4):908-12.

[7] Siddik-Sayyid SM, Aouad MT, Taha SK, et al. A comparison of sevoflurane-propofol versus sevoflurane or propofol for laryngeal mask airway insertion in adults. Anesth Analg 2005;100(4):1204-9.

[8] Taylor IN, Kenny GN. Requirements for target-controlled infusion of propofol to insert the laryngeal mask airway. Anaesthesia 1998;53(3):222-6.

[9] Joo HS, Perks WJ. Sevoflurane versus propofol for anesthetic induction: a meta-analysis. Anesth Analg 2000;91(1):213-9. 